\title{
Localized Edema
}

National Cancer Institute

\section{Source}

National Cancer Institute. Localized Edema. NCI Thesaurus. Code C78437.

Swelling due to an excessive accumulation of fluid at a specific anatomic site. 